\title{
DETERMINAÇÃO DO TEOR DE ÁGUA LIMITE PARA CRIOCONSERVAÇÃO DAS SEMENTES DE IPÊ AMARELO (Tabebuia chrysotrica (Mart. Ex. DC.) Standl.)
}

\author{
Nubênia de Lima Tresena ${ }^{1}$, Mário Eduardo Rangel Moreira Cavalcanti-Mata², \\ Maria Elita Martins Duarte ${ }^{3}$, Ailton M. de Moraes ${ }^{4}$
}

(recebido: 14 de julho de 2009; aceito: 26 de fevereiro de 2010)

\begin{abstract}
RESUMO: Objetivou-se, nesta pesquisa, determinar o teor de água mais adequado à crioconservação das sementes de ipê amarelo quando submetidas à armazenagem à temperatura de $-196^{\circ} \mathrm{C}$, por cinco dias. Foram preparadas amostras de sementes de ipê amarelo com teores de água entre 4 e $12 \%$, base úmida. Foram realizados testes de germinação e vigor das sementes antes e depois da crioarmazenagem. O teor de água limite para a crioconservação do ipê amarelo é de 4\%, base úmida.
\end{abstract}

Palavras-chave: Germinação, armazenamento, criogenia.

\section{DETERMINATION OF THE LIMIT MOISTURE CONTENT FOR CRYOCONSERVATION OF YELLOW IPE SEED (Tabebuia chrysotrica (Mart. Ex. DC.) Standl.)}

\begin{abstract}
The objective of this research was to determine the more appropriate moisture content to the cryoconservation of the "yellow ipe" seeds when they are submitted to storage at the temperature of $-196^{\circ} \mathrm{C}$ per five days. Samples of yellow ipe seeds were prepared with moisture content between 4 and $12 \%, w b$. Test of germination were conducted and vigor of the seeds measured before and after the cryoconservation. The limit moisture content obtained was $4 \%$ w.b. for the cryoconservation of the yellow ipe seeds.
\end{abstract}

Key words: Germination, storage, cryogenic.

\section{INTRODUÇÃO}

A conservação da biodiversidade agrícola tem como objetivo principal resguardar o patrimônio genético atualmente existente, e assegurar para o futuro, a possibilidade de alternativas e soluções para problemas que a agricultura possa vir a enfrentar referentes às pragas, enfermidades e secas, diminuição da produtividade, considerando-se também a não ocorrência de frutificação de algumas espécies; além da intervenção do homem por meio de derrubadas e/ou, queimadas, eliminando áreas produtoras de sementes, entre outras (SOUZA et al., 1979).

Segundo Solbrig (1980), existem restrições quanto à data de semeadura e, muitas vezes é necessário o armazenamento das sementes por longos períodos. Dessa forma, o estudo do armazenamento, longevidade e germinação das sementes de espécies nativas é de suma importância para implantação definitiva dos programas de recuperação de áreas desmatadas, ou mesmo para dar suporte ao paisagismo urbano.

Dentre as espécies florestais, destaca-se o ipê amarelo (Tabebuia chrysotrica (Mart. Ex. DC.) Standl.), cujas sementes apresentam curto período de vida, com anos de baixa ou nenhuma produção, o que limita a sua reprodução, bem como sua utilização em viveiros para reflorestamento e comércio de mudas, tornando-se necessário conhecer suas condições ideais de armazenamento (SOUZA et al., 2005).

Para retardar a degradação das sementes, e para manter a sua conservação, elas devem sofrer um processo de diminuição no seu teor de água, pois de acordo com Barbedo \& Bilia (1998) e Popinigis (1997) o alto teor de água das sementes favorece a elevação da temperatura da massa decorrente do aumento de sua atividade biológica, podendo ser prejudicial para conservação das sementes provocando reações degenerativas e ativação dos microorganismos.

\footnotetext{
${ }^{1}$ Licenciada em Ciências Biológicas, Professora Mestre em Engenharia Agrícola na área de Armazenamento de Produtos Agrícolas Universidade do Vale do Acaraú - Rua Luíza Mota, Catolé - 58000-000 - Campina Grande, PB - nubenia@gmail.com

${ }^{2}$ Engenheiro Agrônomo, Professor e Pesquisador PhD - Departamento de Engenharia Agrícola - Universidade Federal de Campina Grande - Av. Aprígio Veloso, 882, Bodocongó - Cx.P. 10087 - 58109-970 - Campina Grande, PB - mmata@deag.ufcg.edu.br ${ }^{3}$ Engenheira Agrícola, Professora e Pesquisadora PhD - Departamento de Engenharia Agrícola - Universidade Federal de Campina Grande - Av. Aprígio Veloso, 882, Bodocongó - Cx.P. 10087 - 58109-970 - Campina Grande, PB - elita@ deag.ufcg.edu.br ${ }^{4}$ Licenciado em Ciências Biológicas, Professor e Pesquisador PhD - Empresa Estadual de Pesquisa Agropecuária do Estado da Paraíba EMEPA/PB - Avenida Maximiano Machado, 556, Bairro Jaguaribe - 58015110 - João Pessoa, PB - ailtonmmoraes@ hotmail.com
} 
Além do teor de água, os fatores a serem controlados são a temperatura e a umidade relativa do ar. Em alguns bancos de germoplasma a conservação das sementes é feita sob condições controladas a uma temperatura de $10^{\circ} \mathrm{C}$ e umidade relativa do ar de $40 \%$ (MATA, 2006). No entanto, segundo Gonzaga et al. (2003) esse tipo de banco de germoplasma não evita a erosão genética das espécies e recomendam a utilização de bancos criogênicos para a conservação das espécies vegetais.

Para Vieira (2000), a crioconservação é uma técnica que permite manter o germoplasma por vários anos sob temperaturas criogênicas, em geral, $-196^{\circ} \mathrm{C}$. Segundo Villamil (1997), quando as sementes permitem ser crioconservadas à temperatura de $-196^{\circ} \mathrm{C}$, essas podem ter uma longevidade de armazenamento considerada indefinida, pois às temperaturas abaixo de $-130^{\circ} \mathrm{C}$, a atividade metabólica das sementes é mínima e pode ser considerada desprezível. A capacidade das sementes para resistir à imersão em nitrogênio líquido é o ponto chave para crioconservação do germoplasma, por longo prazo e por tempo indefinido.

Alguns autores têm descrito que o porcentual do teor de água das sementes interfere no processo de crioconservação. De acordo com Cunha (1996), o teor de água da semente é, provavelmente, o fator mais crítico para o sucesso da crioconservação, pois se esse teor for muito alto, ocorre morte instantânea da semente durante o processo de congelamento e/ou descongelamento. Segundo Goldfarb et al. (2008), as sementes de pinhão manso podem ser crioconservadas à temperatura de $-196^{\circ} \mathrm{C}$, com teor de água entre 4 a $8 \%$ base úmida, pois sua germinação e o seu vigor não são alterados significativamente. No entanto, o teor de água limite para crioconservação dessas sementes foi estabelecido como sendo $8 \%$, base úmida, uma vez que, se outros teores de água fossem considerados, os custos de secagem seriam envolvidos, propiciando maiores gastos. Segundo Coelho (2006), para as cultivares de algodão herbáceo, colorido BRS 200 Marrom e BRS Verde, o teor de água limite encontra-se entre 6 e $8 \%$ para ambas cultivares.

Como os estudos tecnológicos das sementes são efetivamente o ponto de partida para utilização e exploração de forma racional das espécies nativas, este trabalho propôs-se a determinar o teor de água limite para crioconservação (TALC), das sementes de ipê amarelo (Tabebuia chrysotrica (Mart. Ex. DC.) Standl.).

\section{MATERIAL E MÉTODOS}

Desenvolveu-se o presente trabalho no Laboratório de Sementes do Centro Nacional de Pesquisa do Algodão, CNPA e no setor de Criogenia do Laboratório de Armazenamento e Processamento de Produtos Agrícolas do Departamento de Engenharia Agrí́cola, Campus I, UFCG, ambos localizados em Campina Grande, PB. O material biológico utilizado foi sementes de Ipê amarelo (Tabebuia chrysotrica (Mart. Ex. DC.) Standl.) que foram coletadas na cidade de Campina Grande - PB (cidade que está a uma altitude média de 551 metros acima do nível do mar, com latitude - $07^{\circ} 13$ ' $50^{\prime}$ ', longitude $35^{\circ} 52^{\prime}$ ' 52' 'e uma área que abrange 599,6 $\mathrm{km}^{2}$ ), entre novembro e dezembro de 2006. Após a coleta das sementes foi retirada uma amostra para determinação do teor de água inicial dessas sementes. $\mathrm{O}$ método para essa determinação foi o método oficial da estufa a $105 \pm 2{ }^{\circ} \mathrm{C}$ durante 24 horas, prescrito nas Regras para Análise de Sementes (BRASIL, 1992). O teor de água, em base úmida, foi estabelecido como sendo a média de três repetições e os resultados expresso por meio da equação :

$X \%=\frac{P i-P f}{P i} x 100$

onde:

$P i=$ peso inicial da amostra (gramas);

$P f=$ peso final da amostra (gramas);

$X=$ teor de água em percentagem de base úmida (b.u) \%.

Logo após a determinação do teor de água inicial das sementes, essas foram submetidas ao processo de hidratação ou secagem até alcançarem os teores de água para obtenção do TALC (Teor de Água Limite para a Crioconservação). Foram formados cinco lotes com teores de água ajustados para 4; 6; 8; 10 e 12\% b.u. Na secagem, as sementes foram colocadas em um dessecador contendo sílica gel, sendo cada lote pesado a cada duas horas até que atingisse o peso referente aos teores de água desejados.

Para o umedecimento, as sementes de ipê amarelo foram colocadas em cestas de arame, suspensos por um anel de PVC no interior de recipientes de vidro hermeticamente fechados, contendo $1 / 5$ do seu volume de água destilada (Figura 1), e posteriormente colocados em câmara a $5^{\circ} \mathrm{C}$. As cestas contendo os lotes de sementes foram pesadas a cada duas horas até atingirem os pesos referentes aos teores de água desejados.

Cerne, Lavras, v. 16, n. 2, p. 171-175, abr./jun. 2010 


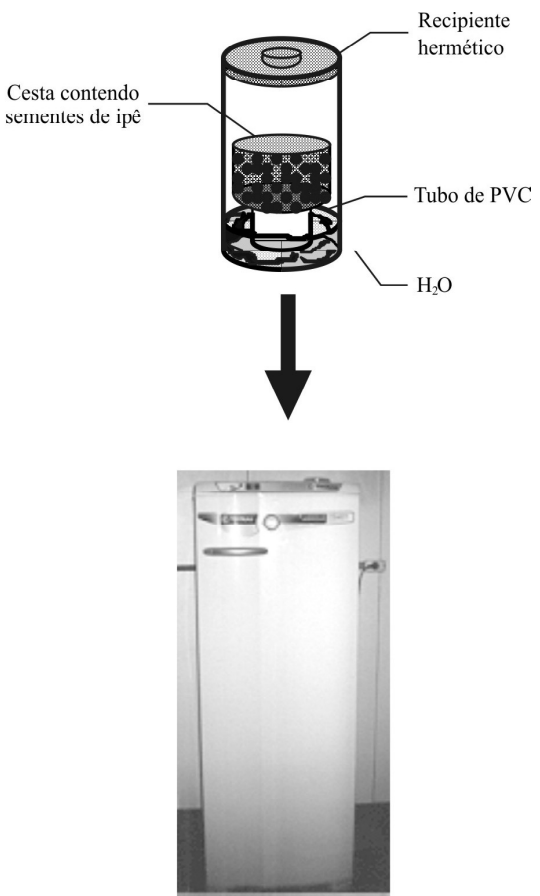

Figura 1 - Recipiente para umedecimento da semente de Tabebuia chrysotrica (Mart. Ex. DC.) Standl.

Figure 1 - Recipient for wetting the Tabebuia chrysotrica (Mart. Ex. DC.) Standl seed.

A perda ou o ganho de água pelas sementes foi determinado por meio da fórmula:

$P f=P i \frac{100-X i}{100-X f}$

em que:

$P f=$ peso final da amostra (grama);

$P i=$ peso inicial da amostra (grama);

$X i=$ teor de água inicial das sementes (\% b.u.);

$X f=$ teor de água final desejada das sementes (\% b.u.).

Ajustados os teores de água para 4; 6; 8; 10 e $12 \%$ b.u., os lotes de sementes foram acondicionadas em canister (Figura 2a), separadas de acordo com os seus teores de água e submetidas ao congelamento em nitrogênio líquido a $-196^{\circ} \mathrm{C}$ por cinco dias em recipientes criogênicos (Figura 2b), que é o tempo necessário para saber se as sementes são crioconserváveis ou não, de acordo com Mata (2006). Decorrido este período de crioconservação, as sementes foram descongeladas à temperatura ambiente pelo período de 8 horas e logo após foram submetidas à avaliação de sua qualidade fisiológica,

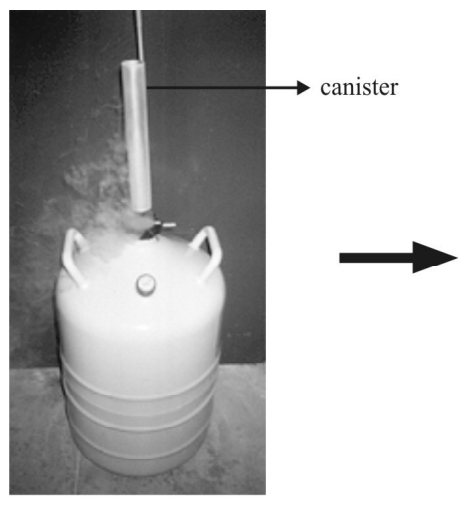

(a)

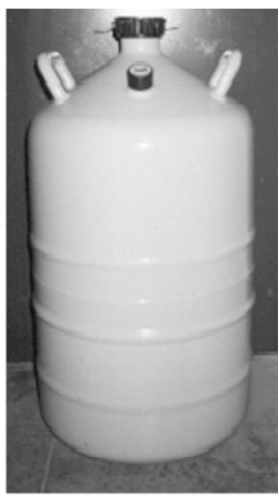

(b)
Figura 2 - Recipientes criogênicos.

Figure 2-Cryogenic recipients.

por meio dos testes da germinação e vigor. Os testes de germinação foram realizados obedecendo-se aos procedimentos prescritos nas Regras para Análise de Sementes (BRASIL, 1992), sendo que a $1^{\mathrm{a}}$ e a $2^{\mathrm{a}}$ contagem foram realizadas com quinze e trinta dias após o início do experimento e foram consideradas plântulas normais aquelas que desenvolveram as estruturas fundamentais, tais como radícula e hipocótilo.

As sementes foram semeadas em papel germitest em recipientes plásticos de $12 \times 12$ x $14 \mathrm{~cm}$, contendo duas folhas na base e uma cobrindo as sementes, sendo umedecidas periodicamente com água destilada e postas em germinador a uma temperatura alternada de $20^{\circ} \mathrm{C}$, durante a noite a partir das 18:00h até 6:00h da manhã do outro dia e $30^{\circ} \mathrm{C}$ a partir das 6:00h até as 18:00h. Esse controle alternado das temperaturas dava-se de forma automática, através do germinador. A umidade relativa estava entre 90 e $95 \%$.

$\mathrm{O}$ vigor das sementes de ipê amarelo foi determinado por meio da $1^{a}$ contagem do teste padrão de germinação. $\mathrm{O}$ outro teste de vigor utilizado foi o peso da matéria seca das plântulas. Neste teste as plântulas foram coletadas após o final do teste padrão de germinação, e foram colocadas em sacos de papel, separados por repetições e postos para secar em estufa termoelétrica regulada a $80^{\circ} \mathrm{C}$, durante 24 horas. Após esse período, as amostras foram retiradas da estufa e colocadas para esfriar em dessecador por 30 minutos. Em seguida, esses sacos contendo as plântulas normais do teste de germinação, foram pesados para determinar o peso da matéria seca total das plântulas normais, obtendo-se o peso médio da matéria seca das plântulas de ipê amarelo pela média aritmética das repetições (VIEIRA \& CARVALHO, 1994).

Cerne, Lavras, v. 16, n. 2, p. 171-175, abr./jun. 2010 
Para utilizar uma amostra comparativa com aquelas crioconservadas, foram também armazenadas sementes de ipê amarelo com teores de água de 4, 6, 8, 10, 12\% b.u durante cinco dias, em sala acondicionada a uma temperatura de $\pm 25^{\circ} \mathrm{C}$, com unidade relativa do ar de $70 \%$.

$\mathrm{O}$ delineamento estatístico empregado foi o inteiramente casualizado, com arranjo fatorial de duas temperaturas $\left(25 \mathrm{e}-196^{\circ} \mathrm{C}\right)$ e cinco teores de água $(4,6,8$, $10,12 \%$ b.u), empregando-se três repetições de 100 sementes por tratamento. A análise de variância e comparação das médias dos tratamentos foi realizada pelo teste de Tukey. O programa computacional utilizado foi ASSISTAT, versão 7.4 (SILVA, 1996).

\section{RESULTADOS E DISCUSSÃO}

A germinação e o vigor das sementes de ipê amarelo com os teores de água descritos e submetidas à armazenagem por cinco dias, à temperatura ambiente de $25^{\circ} \mathrm{C} \pm 2^{\circ} \mathrm{C}$ e imersão em nitrogênio líquido a $-196^{\circ} \mathrm{C}$, encontra-se na Tabela 1. Pode-se constatar que as sementes de ipê amarelo perdem significativamente a germinação e o vigor ( $1^{\mathrm{a}}$ contagem e matéria seca), quando seu teor de água é aumentado de $4 \%$ b.u para $12 \%$ b.u., verificandose que essa diferença significativa se dá mais acentuadamente quando as sementes passam de um teor de água de 4\%b.u. para 6\%b.u.

Observa-se também, que a semente com teor de água acima de $6 \%$, quando submetidas à armazenagem, à temperatura de $-196^{\circ} \mathrm{C}$, diminui a sua germinação para valores abaixo de 7\%, chegando a não mais germinar com um teor de água de $12 \%$ b.u. Ainda em relação à viabilidade dessa espécie, observa-se decréscimo tanto na germinação como no vigor ( $1^{\mathrm{a}}$ contagem e matéria seca) independentemente da temperatura, indicando que essa espécie é muito frágil com relação à sua armazenabilidade e que o teor de água limite para crioconservação da semente de ipê amarelo deve ser de 4 \%b.u. Essa constatação de obter-se um baixo teor de água limite para crioconservação do ipê amarelo está de acordo com as afirmações descritas por Stanwood (1985), em que se observa que as sementes de trevo passam a ser afetadas quando são crioconservadas à temperatura de $196^{\circ} \mathrm{C}$ com teores de água acima de $20 \%$ b.u.

Coelho (2006), determinando o teor de água limite para crioconservação das sementes de duas cultivares de algodão colorido BRS Verde e BRS Marrom, também constatou a necessidade de armazenar sementes com baixos teores de água, pois observou que os melhores índices de germinação e vigor das sementes encontravam-se quando essas estavam com teores de água entre 6 e $8 \%$ b.u.. O autor também verificou que, nos teores mais elevados de água $(10 \%, 12 \%$ e $14 \%)$ houve um decréscimo significativo tanto na germinação como no vigor.

Os valores baixos de teor de água limite para determinadas sementes encontram apoio na literatura, quando Stanwood (1987) descreve que sementes de Sesamum indicum apresentam tolerância ao nitrogênio quando submetidas a um baixo teor de água e que danos provocados nas sementes durante a crioconservação

Tabela 1 - Valores médios da germinação e vigor em função do teor de água das sementes de ipê amarelo (Tabebuia chrysotrica (Mart. Ex. DC.) Standl.), crioconservadas a $-196^{\circ} \mathrm{C}$ e à temperatura ambiente $\left(25^{\circ} \mathrm{C}\right)$, por um período de cinco dias.

Table 1 - Medium Values of the germination and vigor in function of the Pink seeds (Tabebuia chrysotrica (Mart. Ex. DC.) Standl.) moisture content cryoconserved at $-196^{\circ} \mathrm{C}$ and the ambient temperature for period of five days.

\begin{tabular}{|c|c|c|c|c|c|c|}
\hline \multicolumn{7}{|c|}{ Ipê Amarelo } \\
\hline & \multirow{2}{*}{\multicolumn{2}{|c|}{$\begin{array}{c}\text { Germinação } \\
(\%)\end{array}$}} & \multicolumn{4}{|c|}{ Vigor } \\
\hline & & & $1^{\mathrm{a}} \mathrm{C}$ & $(\%)$ & Matéria & (g) \\
\hline \multirow{2}{*}{ T.U.\% b.u. } & Ambiente & Imersão & Ambiente & Imersão & Ambiente & Imersão \\
\hline & $25^{\circ} \mathrm{C}$ & $-196^{\circ} \mathrm{C}$ & $25^{\circ} \mathrm{C}$ & $-196^{\circ} \mathrm{C}$ & $25^{\circ} \mathrm{C}$ & $-196^{\circ} \mathrm{C}$ \\
\hline 4 & $87 \mathrm{aA}$ & $82 \mathrm{aB}$ & $87 \mathrm{aA}$ & $82 \mathrm{aB}$ & $1,68 \mathrm{aA}$ & $1,58 \mathrm{aB}$ \\
\hline 6 & $43 \mathrm{cA}$ & $43 \mathrm{bA}$ & $43 \mathrm{cA}$ & $43 \mathrm{bA}$ & $0,85 \mathrm{cA}$ & $0,86 \mathrm{bA}$ \\
\hline 8 & $45 \mathrm{bA}$ & $7 \mathrm{cB}$ & $45 \mathrm{bA}$ & $7 \mathrm{cB}$ & $0,86 \mathrm{cA}$ & $0,14 \mathrm{cB}$ \\
\hline 10 & $46 \mathrm{bA}$ & $6 \mathrm{cB}$ & $46 \mathrm{bA}$ & $6 \mathrm{cB}$ & $0,90 \mathrm{bA}$ & $0,12 \mathrm{cB}$ \\
\hline 12 & $29 \mathrm{dA}$ & $0 \mathrm{~dB}$ & $29 \mathrm{dA}$ & $0 \mathrm{~dB}$ & $0,58 \mathrm{dA}$ & $0,0 \mathrm{~dB}$ \\
\hline
\end{tabular}

As médias seguidas das mesmas letras maiúsculas nas linhas e minúsculas nas colunas não diferem estatisticamente pelo teste deTukey, ao nível de 5\% de probabilidade

Cerne, Lavras, v. 16, n. 2, p. 171-175, abr./jun. 2010 
podem ocorrer com alto teor de água causando danos às sementes com perda parcial ou total da germinação. Esse fato é ressaltado por Chandel et al. (1995), que verificaram que sementes recalcitrantes de cacau (Theobroma cacao) e jaca (Artocarpus integrifolius), crioconservadas com os teores de água de 24 e $35 \%$ b.u., não toleram o congelamento a $-196^{\circ} \mathrm{C}$. Sementes de cacau e jaca sobrevivem após a crioconservação com teor de água de $14 \%$.

\section{CONCLUSÕES}

O melhor porcentual de germinação e vigor $\left(1^{\mathrm{a}}\right.$ contagem e matéria seca) das sementes de ipê amarelo (Tabebuia chrysotrica (Mart. Ex. DC.) Standl.) foi obtido quando essas sementes foram crioconservadas $\left(-196^{\circ} \mathrm{C}\right)$, com um teor de água de $4 \%$ b.u.

A semente de ipê amarelo (Tabebuia chrysotrica (Mart. Ex. DC.) Standl.) com teores de água acima de $4 \%$ b.u. tem sua germinação e vigor diminuídos significativamente, portanto o teor de água limite para criconservação de sementes de ipê amarelo é de 4\%b.u.

\section{REFERÊNCIAS BIBLIOGRÁFICAS}

BARBEDO, C. J.; BILIA, D. A. C. Evolution of research on recalcitrant seeds. Scientia Agrícola, Piracicaba, v. 55, p. 4548, 1998. Número especial.

BRASIL. Ministério de Agricultura. Regras para análise de sementes. Brasília, 1992. 365 p.

CHANDEL, K. P. S.; CHANDURY, R.; RADHAMANI, J.; MALIK, S. K. Desiccation and freezing sensitivity in recalcitrant seed of tea, cocoa and jackfruit. Annals of Botany, London, v. 76, n. 5, p. 443-450, 1995.

COELHO, R. R. P. Aspectos da crio-preservação de sementes de duas cultivares de algodão colorido (Gossypium hirsutum L. raça latifolium Hutch.). 2006. 89 f. Tese (Doutorado em Agronomia) - Universidade Federal da Paraíba, Areia, 2006.

CUNHA, R. da. Métodos alternativos para conservação de germoplasma-semente. In: PUIGNAU, J. P. (Ed.). Conservación de germoplasma vegetal. Montevideo: IICA, 1996. p. 123128. (IICA- PROCISUR. Dialogo, 45).

GOLDFARB, M.; MATA, M. E. R. M. C.; BRAGA, M. E. D. Teor de água limite para crioconservação de sementes de pinhão manso (Jatropha curcas L.). Revista Brasileira de Produtos Agroindustriais, Campina Grande, v. 10, n. 1, p. 121-129, 2008
GONZAGA, T. W. C.; MATA, M. E. R. M. C.; SILVA, H.; DUARTE, M. E. M. Crioconservação de Sementes de aroeira (Astroniumurundeuva Engl.), e baraúna (Schinopsisbrasiliensis Engl.). Revista Brasileira de Produtos Agroindustriais, Campina Grande, v. 5, n. 2, p. 145-154, 2003

MATA, M. E. R. M. C. Armazenagem criogênica de sementes de importância para a biodiversidade e de relevância para a economia da região semi-árida. [S.1.: s.n.], 2006. 56 p. Projeto PROEX.

POPININGIS, F. Fisiologia de sementes. Brasília: AGIPLAN, 1997. $315 \mathrm{p}$.

SILVA, F. de A. S. The ASSISTAT software: statistical assistance. In: INTERNATIONAL CONFERENCE ON COMPUTERS IN AGRICULTURE, 6., 1996, Cancun. Anais... Cancun: American Society of Agricultural Engineers, 1996. p. 294-298.

SOLBRIG, O. T. Demography and evolution in plant populations. Berkeley: University of California, 1980. 222 p.

SOUZA, S. M. de; PIRES, L. E.; LIMA, P. C. F. Influência de embalagens e condições de armazenamento na longevidade de sementes florestais. In: CONGRESSO BRASILEIRO DE SEMENTES, 1., 1979, Curitiba. Resumos... Brasília: ABRATES, 1979. p. 78.

SOUZA, V. C.; BRUNO, R. L. A.; ANDRADE, L. A. Vigor de sementes armazenadas de ipê amarelo (Tabebuia serratifolia (Vahl.) Nich). Revista Árvore, Viçosa, v. 29, n. 6, p. 833-841, 2005.

STANWOOD, P. C. Survival of sesame seeds at the temperature $\left(-196^{\circ} \mathrm{C}\right)$ of liquid nitrogen. Crop Science, Madsonn, v. 27, p. 327-331, 1987.

VIEIRA, M. L. C. Conservação de germoplasma in vitro. Biotecnologia Ciências e Desenvolvimento, Brasília, v. 3, n. 14, p. 18-20, 2000.

VIEIRA, R. D.; CARVALHO, N. M. Testes de vigor em sementes. Jaboticabal: FUNEP, 1994. 164 p.

VILLAMIL, P. Crioconservación de semillas. In: CONGRESSO BRASILEIRO DE ENGENHARIA AGRÍCOLA, 26., 1997, Campina Grande. Minicurso... Campina Grande: UFPB/SBEA, 1997. $55 \mathrm{p}$.

Cerne, Lavras, v. 16, n. 2, p. 171-175, abr./jun. 2010 
